$$
\begin{aligned}
& \text { بررسى اثر سندروم كلستاز برتغييرات بافتى هستهاى مجاور بطنى و فوق بصرى هيبوتالاموس مغز } \\
& \text { موشهاى صحر ايى نر نزاد ويستار }
\end{aligned}
$$

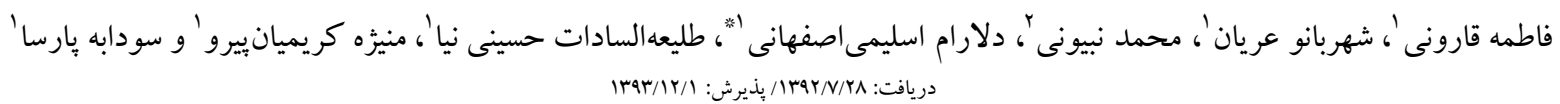

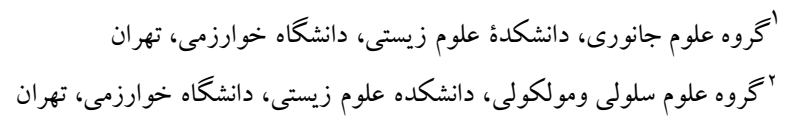

$$
\begin{aligned}
& \text { eslimi@khu.ac.ir :مسئول مكاتبات }
\end{aligned}
$$

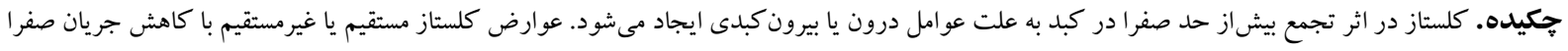

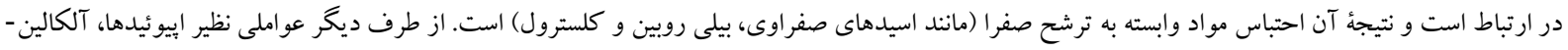

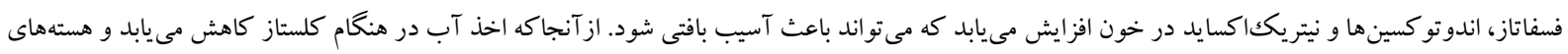

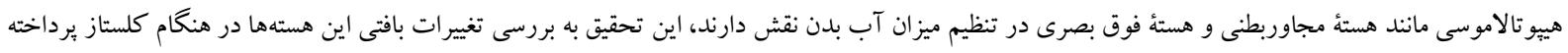

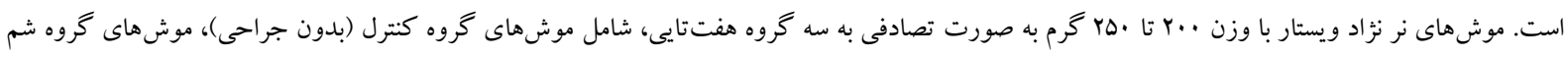

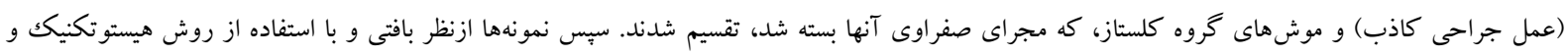

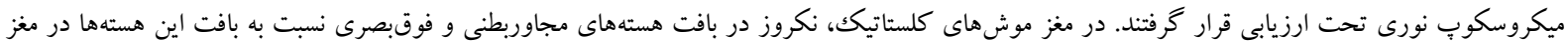

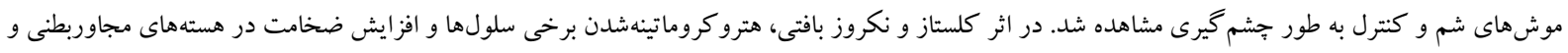

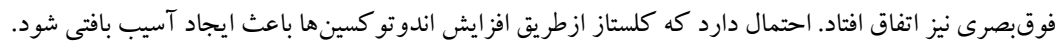

$$
\begin{aligned}
& \text { وازههاى كليدى. اسيدهاى صفراوى، بيلى روبين، كلسترول، اندوتو كسين، نكروز }
\end{aligned}
$$

\title{
The histopathological effects of cholestasis on hypothalamic paraventricular and supraoptic nucleus on male wistar rats
}

Fatemeh Gharoony ${ }^{1}$, Shahrbanoo Oryan ${ }^{1}$, Mohammad Nabiuni ${ }^{2}$, Delaram Eslimi Esfahani ${ }^{1}$, Talieh Sadat Hosseinynia ${ }^{1}$, Manijeh Karimian Peiro ${ }^{1}$ and Soudabeh Parsa ${ }^{1}$

Received 20.10.2013 / Accepted 20.02.2015

\begin{abstract}
${ }^{1}$ Department of Animal Biology, Faculty of Biological Sciences, Kharazmi University, Tehran, Iran ${ }^{2}$ Department of Cell and Molecular Biology, Faculty of Biological Sciences, Kharazmi University, Tehran, Iran *Correspondent author: eslimi@khu.ac.ir
\end{abstract}

\begin{abstract}
Cholestasis caused by the excessive accumulation of bile within the liver, due to intrinsic or extrinsic factors. Cholestasis side effects are associated directly or indirectly with the reduction of bile flow and the confinement of materials related to bile secretion (such as bile acids, bilirubin, and cholesterol). On the other hand, some factors such as opioids, alkaline phosphatase, endotoxin and nitric oxide increase in blood, which could cause tissue damage. Since water intake reduces during cholestasis and hypothalamic nuclei such as paraventricular and supraoptic nucleuses are involved in the regulation of body water; Therefore, in this study, the histopathological changes of hypothalamic nuclei were evaluated. Male Wistar rats weighing 200-250 g were randomly divided into three groups. Three sets of seven groups were unoperated control, sham-operated and bile duct-ligated rats. The tissue samples were analyzed using histotechnique and light microscope. Brain tissue necrosis in paraventricular and supraoptic nucleus in cholestatic rats increased, but in the sham and control rats no changes were observed and also cholestasis caused wrinkle chromatic nuclei and increased thickness of hypothalamic nuclei. Because endotoxin causes tissue trauma, it is likely increased endotoxin may leads to tissue changes in the brain.
\end{abstract}

Keywords. bile acids, bilirubin, cholesterol, endotoxin, necrosis 
بهواسطة حفره بطن سوم به طور قرينه به دو نيمة راست و جِب

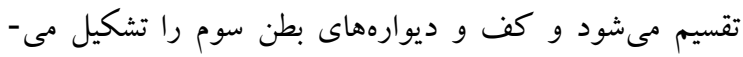
دهد. در هييوتالاموس هستههايى وجود دارند كه از اجتماع وني

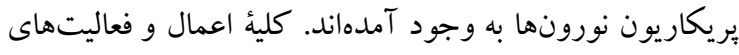

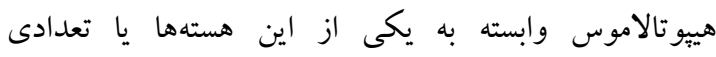
از آنهاست. اين هستهها ازطريق اعصاب و عروق با غدة هييوفيز

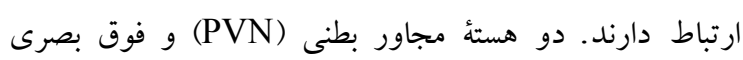
در اخذ آب نقش دارند و با آزادسازى هورمون (SON)

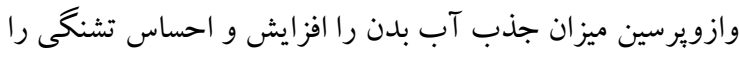

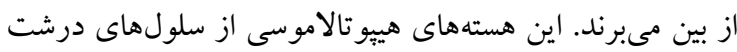

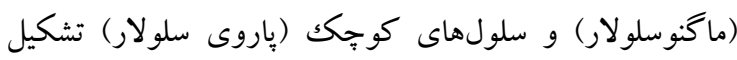

شدهاند (Oryan \& Valizadegan, 2009). نوشيدن آب بِاسخى به كاهش حجم خون است كه بهوسيلة دو

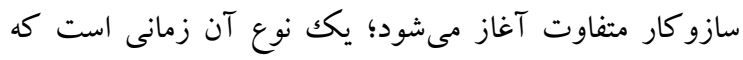

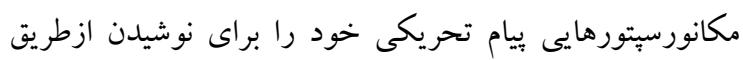

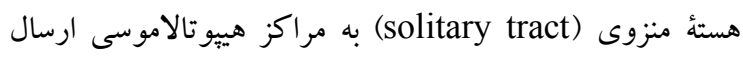
مى كنند. مركز تنظيمى مهم ديخرى كه در اخذ آب نقش دارد،

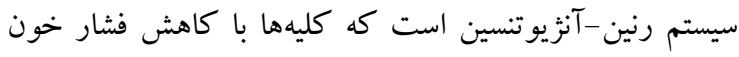

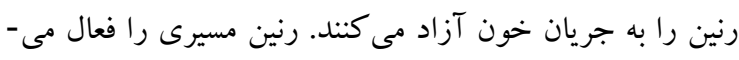

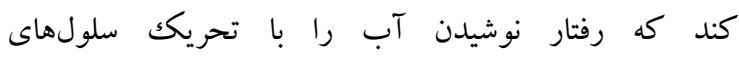
ماكنوسلولار SON و SVN موجب مىشود و در در اين مورد

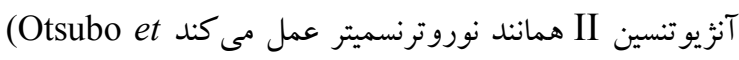

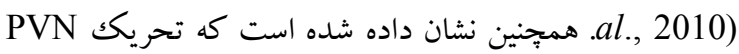
اخذ آب را افزايش مىدهد (Takahashi et al., 2001). با توجه به اينكه مر كز تنظيم تشنكى و نوشيدن در هستهاى مجاور

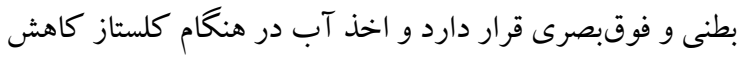

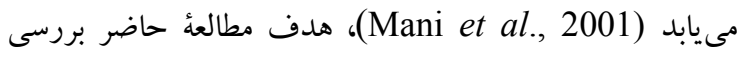

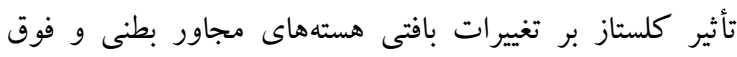
بصرى هييوتالاموس است.

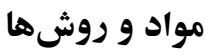

\section{حيوانات و شرايط آزمايش}

اين مطالعه در آزمايشكاه فيزيولوزى جانورى دانشكدة علوم

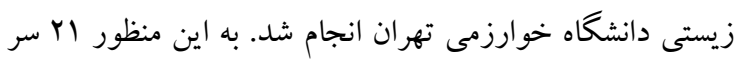

كلستاز ازنظر فيزيولوزيك،، به توقف يا كاهش جريان صفرا در كاناليكولهاى صفراوى كفته مى شود (Reyes et al., 1993).

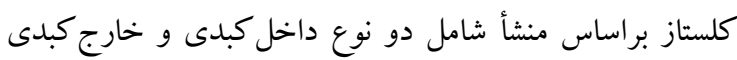
است. كلستاز داخل كبدى بر اثر اختلال در عملكرد هياتوسيتها و كلستاز خارج كبدى به دليل عواملى نظير سنك هاى صفراوى، تومورهاى بانكراس و كيسٔصفرا ايجاد مىشود Moezi et

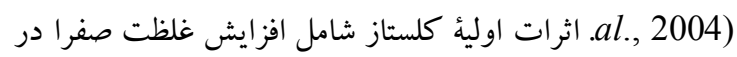
سرم (كه در غلظتهاى بالا سمى است) و كاهش ترشح صفرا

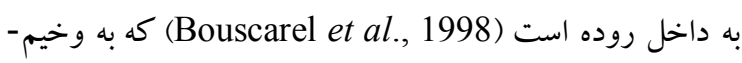
ترشدن بيمارى كبدى و ايجاد بيمارى سيستميك منجر مى شود (Kountouras et al., 1984) فيبروز و سيروزكبدى اتفاق مىافتد (Moezi et al., 2004).

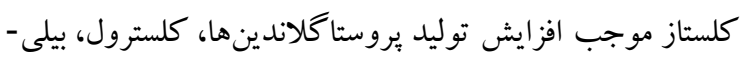

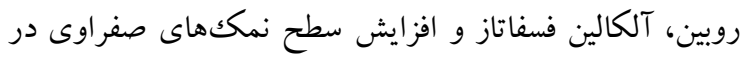

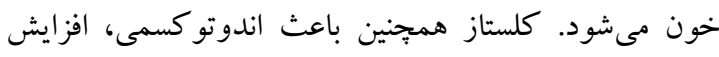
توليد نيتريك اكسايد (Moezi et al., 2004)، ايجاد تغييرات

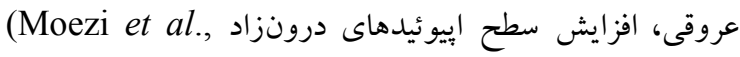
-2004; Borhani et al., 2005) (Hajrasouliha et al., 2004; Hasanein et al., شود 2007; Zarrindast et al., 2012) و نوزادى مشاهده گرديده است (Molina et al., 1998) كلستاز Jones et al., 1999; Matthai et al., 2001) باردارى بر اثر نقص زنتيكى ايجاد و موجب نقص مادرزادى مىشود و كلستاز نوزادى بر اثر آترزى مجراى صفراوى و هياتيت

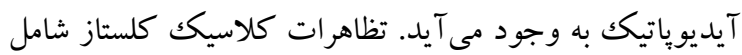
زردى و خارش است. علاوه بر آن، تظاهرات بالينى ديخرى مانند

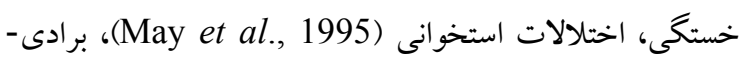
كاردى، تغيير در عملكرد تنفسى و ريها واخلات و نارسايى كليه نيز

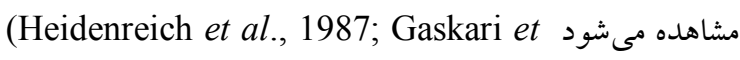
al., 2002; Farajzadeh Deroee et al., 2010) هييو تالاموس منطقة كو جكى از مغز است كه در عقب و بايين مغز جلويى و در جلو و بالاى مغز ميانى قرار دارد. هييو تالاموس 
از آن برشهاى 9 ميكرونى گرفته شد. رنغكآميزى (Merck)

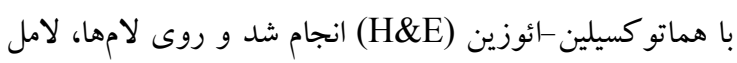

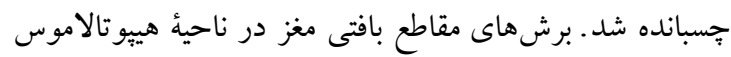

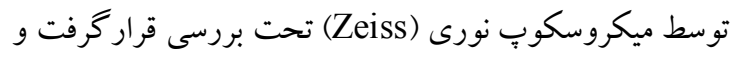
با استفاده از ميكرو گرافهاى تهيهشده از اين لامها، اختلافات

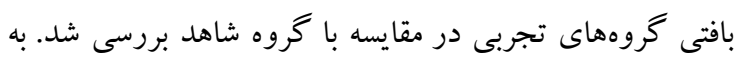

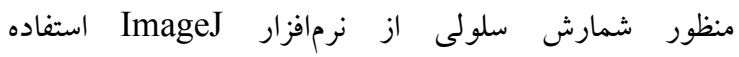
شد (Lavazza et al., 2010). ضخامت هستهاى SON ومار و

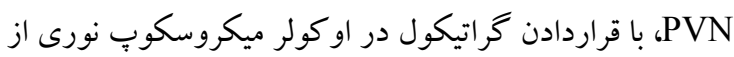
ابتدا تا انتهاى هستهها برحسب ميكرومتر اندازهيرى شدرد

\section{روش و ابزار كردآورى اطلاعات}

محاسبها با استفاده از تحليل واريانس يككطرفه براى مقايسٔ

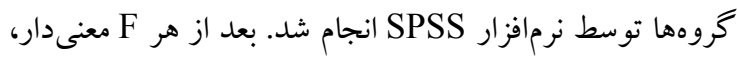
تحليل به كمك Post hoc tukey' test ادامه يافت. ازلحاظ

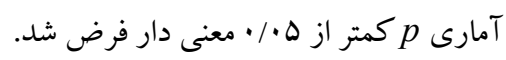

نتايج الف - يافتههاى كيفى: مشاهدات ميكروسكويى نشاندهندة

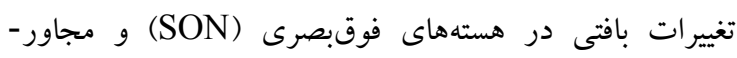

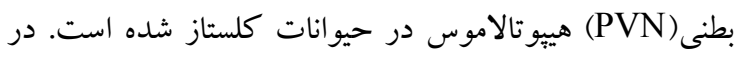

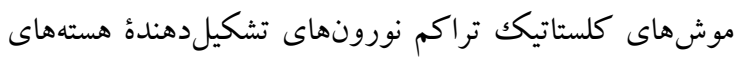
كاهش يافته و مورفولوزى سلولهاى تشكيل PVN و SON دهنده تغيير كرده است و سلولها كو خك و خرو كيده شدهاند. همجنين هتروكروماتينهدن سلولها و ائوزينوفيلهشدن بافت هستها مشاهدهشد. در شكل 1 مقايسة اسلايدها نشان مىدهد

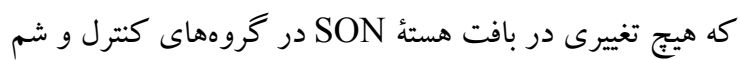
قابل مشاهده نيست. درصورتى كه با بررسى اين (C B B (B)

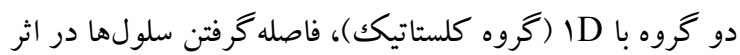

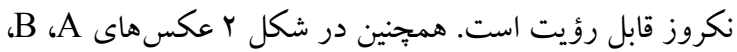
و C كه كروههاى كنترل و شم هستة PVN را نشان مىدهند، تغييرى در ساختار اين هسته ايجاد نشده است، درصورتى كه در هر rD كه، نمونه كلستاتيك است، هتروكروماتينهدن هستها و و

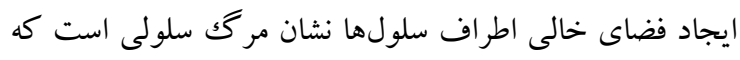
در حالت كلستاتيك به ميزان زيادى در بافت هسته PVN

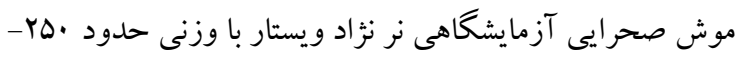
F Y...

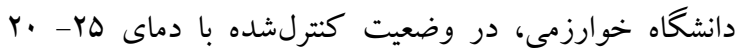

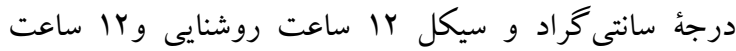
تاريكى قرار گرفتند. كلئ موشها دسترسى آزادانه به آب آب آل

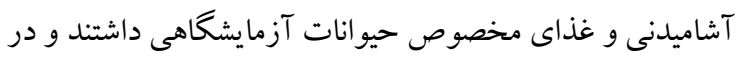
وضعيت يكسان نخهدارى شدند.

\section{جراحى كلستاز}

موشها به سه گروه هفت تايى كنترل، شم (جراحى ساختكى

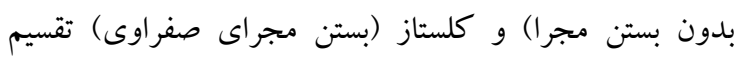

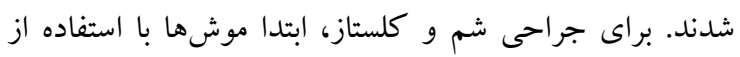

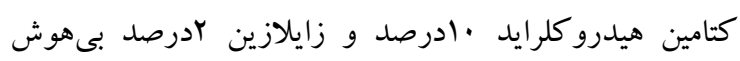

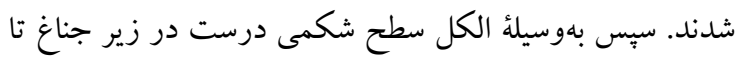

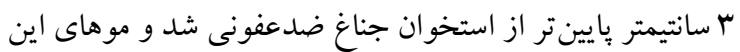
ناحيه با تيغ تراشيده و يوست و عضله در دو مرحلة جدا برش زده شد. سبس با كمكك ينس سر كج مجراى صفراوى مشترك ترك

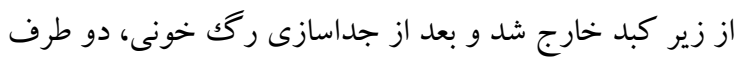

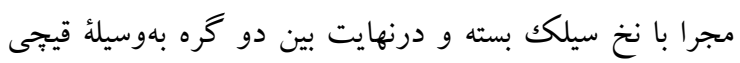

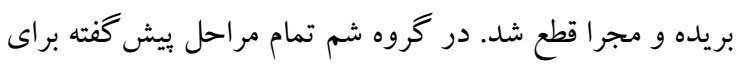

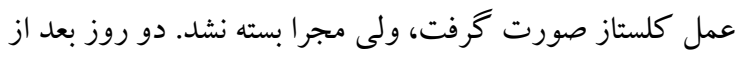
مسدودكردن مجراى صفراوى در حيوانات نشانهاى كلستاز (زردى، ادرار تيره و اسهال جرب) مشاهده شد كه به عنوان شاخص ايجاد كلستاز در نظر خرفته شد.

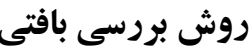

دو و جهارهفته بِساز كلستاز، براى خارج كردن مغز، ابتدا سر

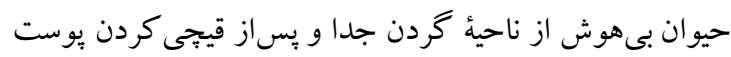

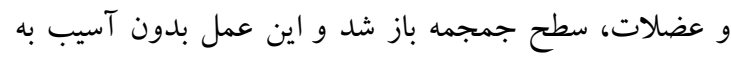

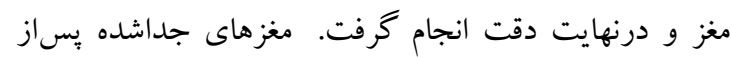

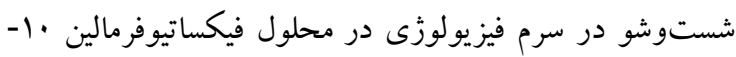
درصد قرار گرفت تا به طور كامل تثبيت شوند. مراحل آماده سازى شامل آبگيرى با درجات صعودى الكلاتيليك و ورات شفافسازى بهوسيلة تولوئن بود. بافت پِ إس ازشفافسازى به

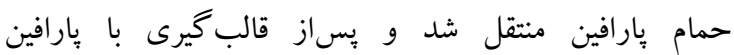




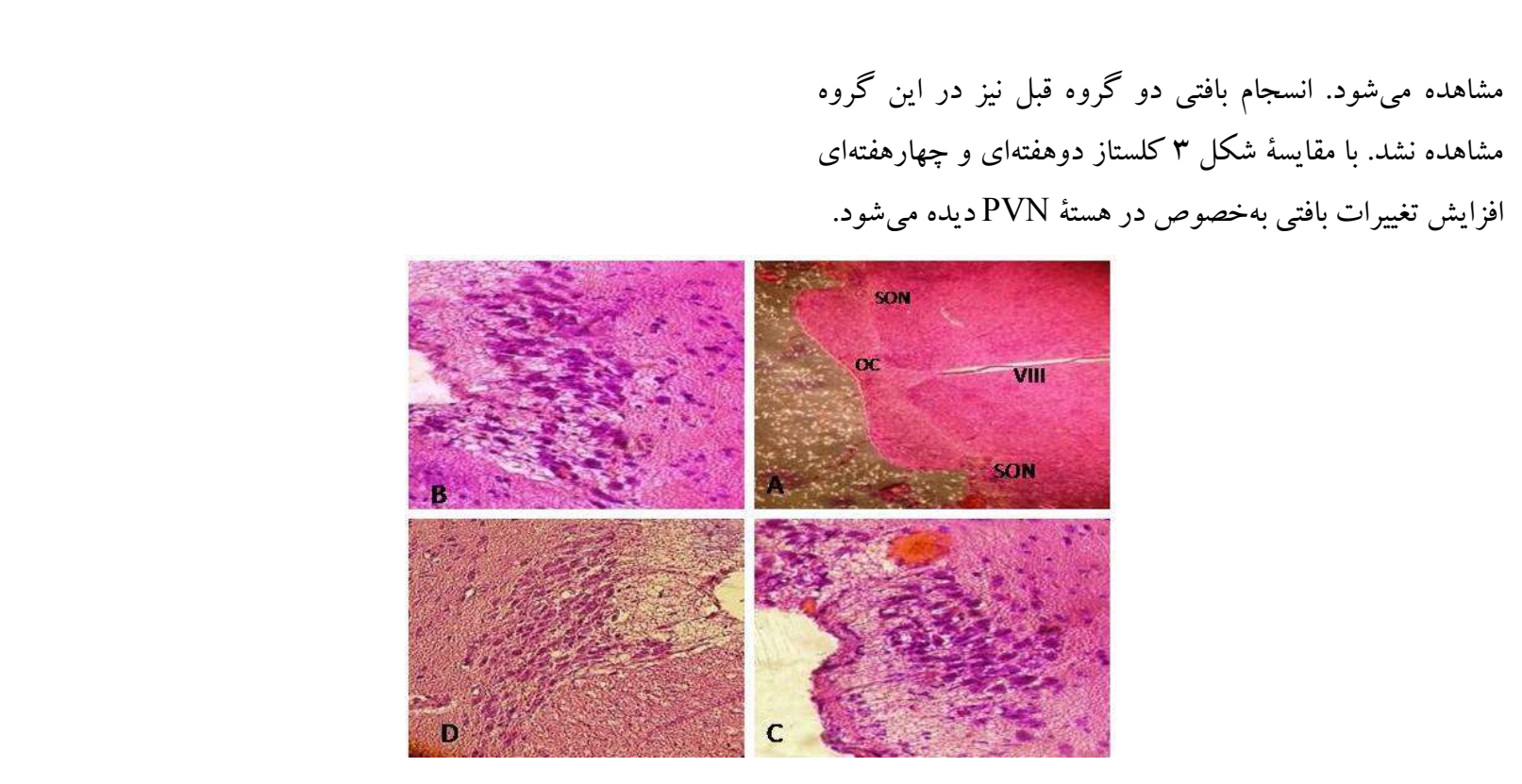

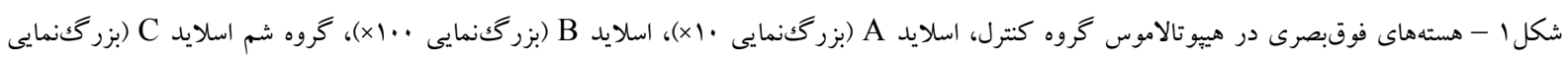

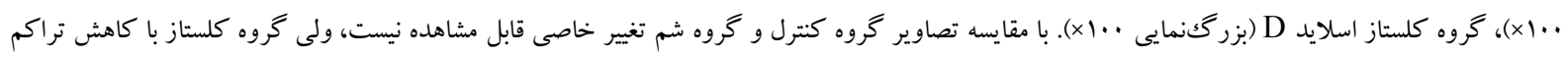

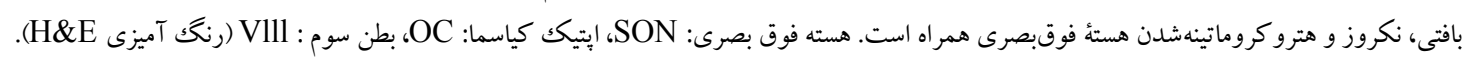
Fig. 1. Supra optic nucleus of hypothalamus, A: Control (10X), B: Sham (100X), C: Cholestasis (100X). Brain tissue necrosis and wrinkle chromatic nuclei in supra optic nucleus in cholestatic rats were increased, but in the sham and control rats no changes were observed (H\&E).
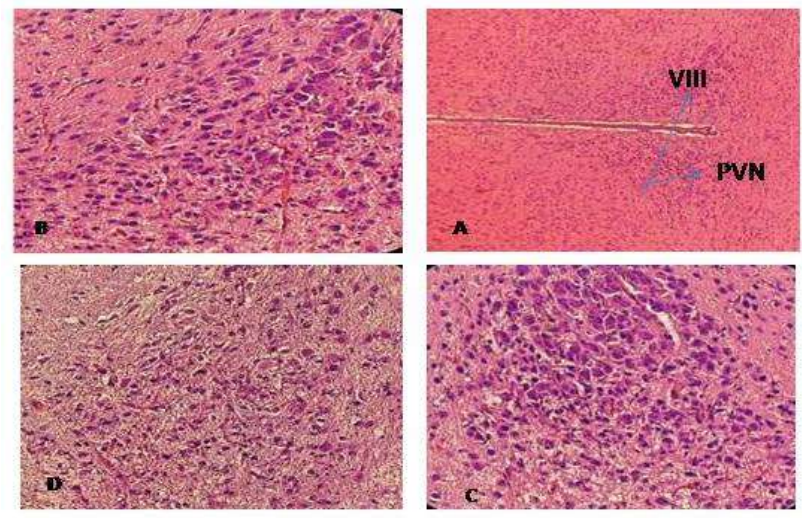

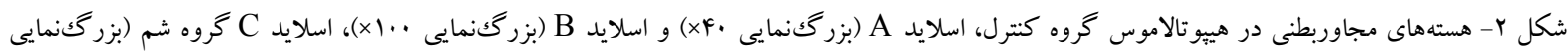

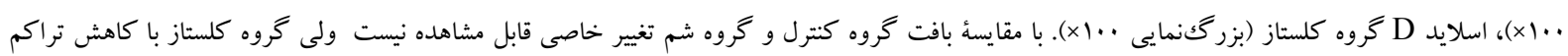

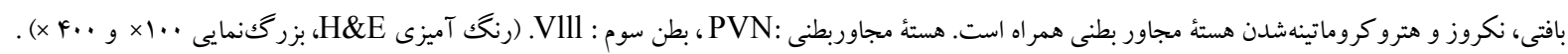

Fig. 2. Para ventricular nucleus of hypothalamus, A: Control (40X), B: Sham (100X), C: Cholestasis (100X). Brain tissue necrosis and wrinkle chromatic nuclei in Para ventricular nucleus in cholestatic rats were increased, but in the sham and control rats no changes were observed (H\&E). 


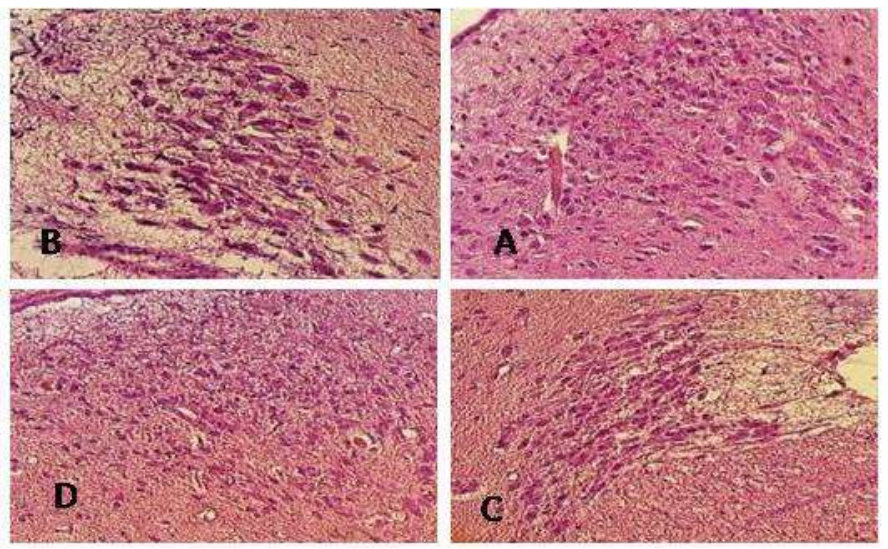

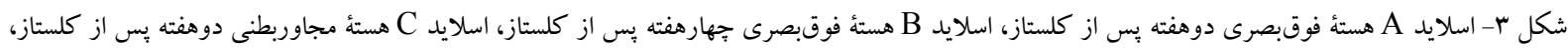

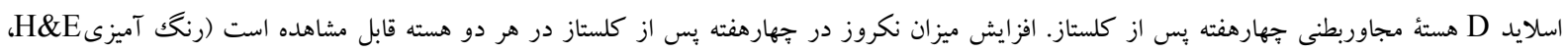

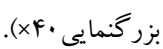

Fig. 3. A: Supra optic nucleus two weeks after BDL. B: Supra optic nucleus four weeks after BDL. C: Para ventricular nucleus two weeks after BDL. D: Para ventricular nucleus four weeks after BDL. Tissue necrosis in two nuclei were increased after four weeks (H\&E- 40X).

$$
\begin{aligned}
& \text { دست آمده از ضخامت اين هستها، به صورت جدول مقايسهاى } \\
& \text { حاصلشد. همجنين درصد نكروز در بافت هستهاى مجاور } \\
& \text { بطنى و فوق بصرى محاسبه شد كه نسبت به نمونهاى كنترل و } \\
& \text { شم (جدول r) افزايش يافته است. }
\end{aligned}
$$

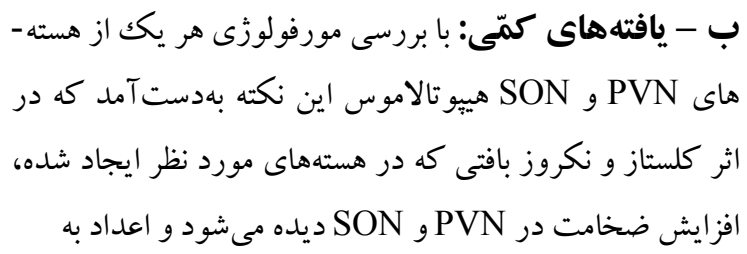

\begin{tabular}{|c|c|c|}
\hline 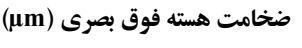 & ضخامت هسته مجاور بطنى ( & 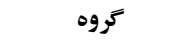 \\
\hline$r V / I F \pm r / r$ & $19 r / \Delta \Delta \pm \Delta / r$ & كنترل \\
\hline$r q / Y \Lambda \pm Y / \Delta$ & $19 \Delta / N 1 \pm \kappa / \Lambda$ & شم \\
\hline$F / / 4 r \pm 1 / 4 * N$ & $\Gamma \mu F / T \Lambda \pm V / \Delta * N$ & دو هفته يس از كلستاز \\
\hline$\kappa r / \ell F \pm r /$ *N & $r Y I / F Y \pm r / Y * N$ & جهار هفته بِس از كلستاز \\
\hline
\end{tabular}

$$
\text { جدول ا- ضخامت هستهاى مجاور بطنى و فوق بصرى در گروههاى كنترل، شم و كلستاز، Mean }
$$

Table 1. Supra optic and Para ventricular nuclei thickness in control, sham and cholestasis. Mean \pm SE, $p<0.05$. 


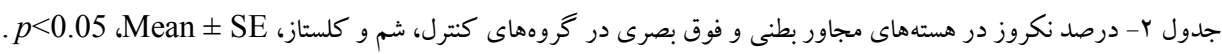

Table 2. Supra optic and Para ventricular nuclei necrosis percentages in control, sham and two or four weeks after cholestasis. Mean $\pm \mathrm{SE}, p<0.05$.

\begin{tabular}{|c|c|c|}
\hline درصد نكروز & درصد نكروز & تروه \\
\hline $19 / 9 \pm \cdot / 49$ & $\mid F / r \Lambda \pm \cdot / F r$ & كتترل \\
\hline$|V / r \pm \cdot / \mathrm{N}|$ & $|F / A V \pm \cdot / F|$ & 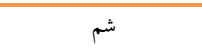 \\
\hline$r Y / \Delta \Delta \pm \cdot / N \Lambda * \aleph$ & $r / N \pm 1 / r * N$ & دو هفته پِس از كلستاز \\
\hline$\kappa V / 10 \pm \cdot / * q \square * \aleph$ & $\kappa \cdot / \Lambda \pm r / r a * \aleph$ & جِهار هفته بِ از كلستاز \\
\hline
\end{tabular}

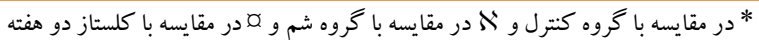

(Huerta et al., در آغاز آسيبهاى عصبى شركت دارد

علاوه بر موارد كفته شده، كلستاز مرتبط با افزايش آنداز آندوتو كسينها مىباشد و آندوتو كسينها نيز در مغز آسيب با فران شدتهاى متفاوت ايجاد مى كند (Harry et al., 1999).

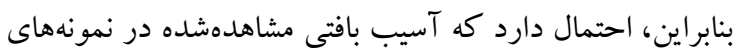
كلستازيس در هسته هاى هييو تالاموسى، كه در اين مطالعه به آن

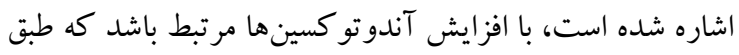
مطالعات كذشته در كلستاز رخ مىدهند. مطالعات نشان دادهاند كه كلستاز، با تغيير ميزان هورمون وازويرسين نيز همراه است. تحقيقات نشان داده كه ترشح دهان

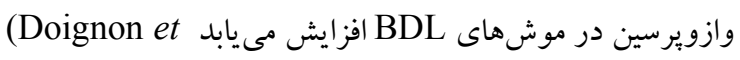
(al., 2011; Cunningham et al., 2012) افزايش وازويرسين در سيروز كبدى مىتواند بهعلت كاهش زياد در حجم و فشار خون باشد (Cunningham et al., 2012).

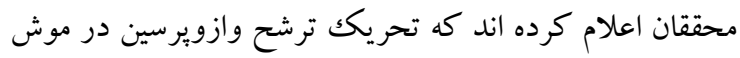

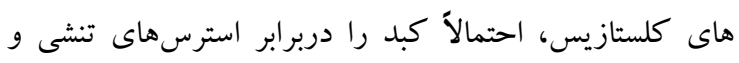

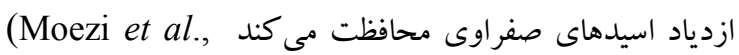
(2004. افزايش تعدادى از فاكتورها ازجمله نمككهاى مافي
با توجه به يافتهاى اين مطالعه، كلستاز مىتواند باعث افزايش

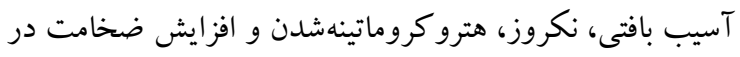
هستهاى فوقبصرى و مجاوربطنى شود. محققان نشان دادهاند، در موشهايى كه مجراى صفراوى آنها بسته مىشود هايير آمونيا رخ مىدهد كه به فعاليت ميكرو كليال در مغز مىانجامد و در-

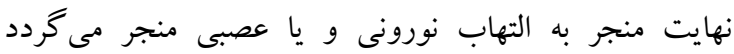
(Rodrigo et al., 2010)

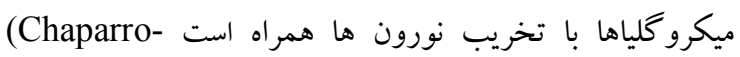

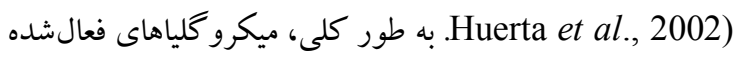

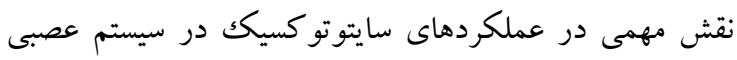
دارند كه هايت به آسيبافتى منجر مىشود. محققان اظهار كردهاند كه ميكرو كلياهاى فعالشده، تركيبات سيتوتو كسيكك فراوانى ازجمله NO، بروتئاز، سيتو كيتزهاى التهابى و ه را رآزاد مى كنند (Vincent et al., 1998). بنابر اين هايير آمونيا،

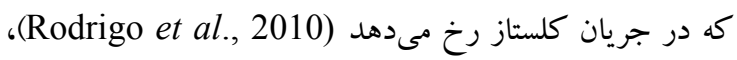
احتمالاً مى تواند يكى از دلايل آسيب به هستههاى فوقبصرى و ودان

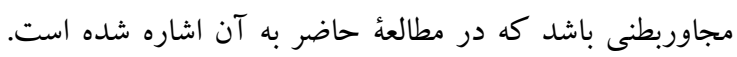
همجنين طبق مطالعات صورت گرفته در سيروز كبدى، بيان (Tumor necrosis factor $\alpha$ ) TNF- $\alpha$ 
2007; Cauli et al., 2009; Yool et al., 2009)

مطالعات نشان دادهاند، با افزايش تو كسىسيتى در مغز، influx و

efflux

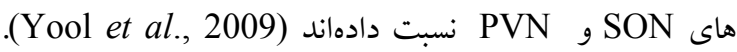

درنهايت ازآنجاكه در موشهاى كلستاتيك اندوتوكسينها،

اسيدهاى صفراوى، إيوئيدها و غيره افزايش مى يابند و هايير -

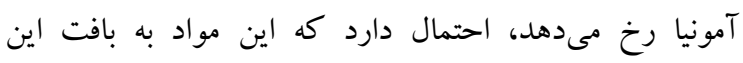

هستهاى مؤثر در اخذ آب آسيب يزنند. در -مجموع براى نتيجه -

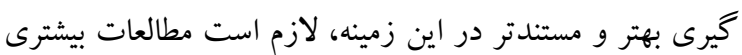

صورت يذيرد.

منابع / References

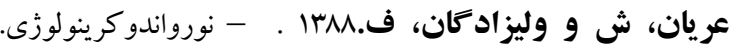

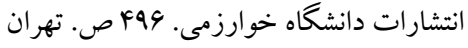

Borhani, A., Houshmand, G., Samini, M., Narimanian, K., Hajrasouliha, A., Tavakoli, S. and Ebrahimi, F. 2005. A2 adenoreceptor subsensitivity in mesenteric vascularbed of cholestatic rats: The role of nitric oxid and endogenous opioids. - The European Journal of Pharmacology 514: 183-189.

Bouscarel, B., Matzuzalzi, Y. and Lee, M. 1998. Changes in G-protein expression account for impaired modulation of hepatic AMP formation after BDL ligation. - The American Journal of Physiology 274: 1151-1159.

Cauli, O., Rodrigo, R., Liansola, M., Montoliu, C., Monfort, P. and Piedrafita, B. 2009. Glutamatergic and gabaergic neurotransmission and neuronal circuits in hepatic encephalopathy. The Journal of Metabolic Brain Disease 24: 6980 .

Chaparro-Huerta, V., Rivera-Cervantes, M., Torres-Mendoza, B. and Beas-Zarate, C. 2002. Neuronal death and tumor necrosis factor-a response to glutamateinduced excitotoxicity in the cerebral cortex of neonatal rats. - The Journal of Neuroscience Letters 333: 95-98.

Cunningham, J.T., Nedungadi, T.H., Walch, J.D., Nestler, E.J. and Gottlieb, H.B. 2012.

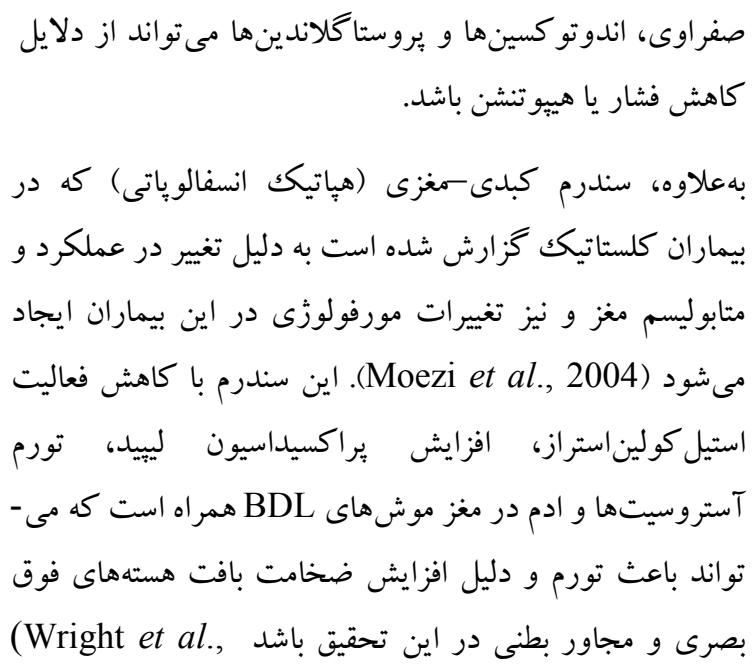

FosB in the supraoptic nucleus contributes to hyponatremia in rats with cirrhosis. - American Journal of Physiol. Regulatory Integrative and Comparative Physiology 303: 177-185.

Doignon, I., Julien, B., Lanneau, V.S., Garcin, I., Alonso, G., Nicou, A., Monnet, F., Gigou, M., Humbert, L., Rainteau, D., Azoulay, D., Castaing, D., Gillon, M., Samuel, D., DuclosVallée, J.C.H. and Tordjmann, T.H. 2011. Immediate neuroendocrine signaling after partial hepatectomy through acute portal hyperpressure and cholestasis. - The Journal of Hepatology 54: 481-488.

Farajzadeh Deroee, A., Ghazi Nezami, B., Ejtemaei Mehr, S.H., Hosseini, R., Hassanzadeh Salmasi, A., Shafaat Talab, S., Jahanzad, I. and Dehpour, A.R. 2010. Cholestasis induced nephrotoxicity: The role of endogenous opioids. - The Journal of Life Sciences 86: 488-492.

Gaskari, S.A., Mani, A.R., Ejtemaei-Mehr, S., Namiranian, K., Homayoun, H., Ahmadi, H. and Dehpour, A.R. 2002. Do endogenous opioids contribute to the bradycardia of rats with obstructive cholestasis? - The Journal of Fundamental \& Clinical Pharmacology 16: 273279.

Hajrasouliha, A.R., Tavakoli, S., JabehdarMaralani, P., Shafaroodi, H., Borhani, A.A., Houshmand, G., Sadeghipour, H., Dehghani, M. and Dehpour, A.R. 2004. Resistance of 
cholestatic rats against epinephrine-induced arrhythmia: the role of nitric oxide and endogenous opioids. - The European Journal of Pharmacology 499: 307-313.

Harry, D., Anand, R., Holt, S., Davies, S., Merley, R., Frnando, B., Goodier, D. and Moore, K. 1999. Increased sensitivity to endotoxemia in the bile duct ligated cirrhotic Rat. - The Journal of Hepatology 30(5):1198-205.

Hasanein, P., Parviz, M., Keshavarz, M., Javanmardi, K. and Ghaseminejad, M. 2007. Modulation of cholestasis-induced antinociception in rat two NMDA receptor antagonists: MK-801 and magnesium sulfate. - The European Journal of Pharmacology 554: 123-127.

Heidenreich, S., Brinkema, E., Martin, A., Dusing, R., Kipnowski, J. and Kramer, H.J. 1987. The kidney and cardiovascular system in obstructive jaundice: functional and metabolic studies in conscious rats. - The Journal of Clinical Science 73: 593-599.

Jones, E.A. and Bergasa, N.V. 1999. The pruritus of cholestasis. - The Journal of Hepatology 29: 1003-1006.

Kountouras, J., Billing, B.H. and Scheuer, G.W. 1984. Prolonged bile duct ligation, a new experimental model for cirrhosis in the rat. - The British Journal of Experimental Pathology 305: 305-311.

Lavazza, C., Carlo-Stella, C., Giacomini, A., Cleris, L. and Righi, M. 2010. CD34 cells engineered to express membrane-bound tumor necrosis factor-related apoptosis-inducing ligand target both tumor cells and tumor vasculature. -

The Journal of Gastroenterology 139: 675-684.

Mani, A.R., Nahavandi, A., Mani, A.H. and Dehpour, A.R. 2001. Role of nitric oxide in hypodipsia of rats with obstructive cholestasis. The Journal of Pharm Pharmacology 53: 277-81.

Matthai, J. and Poul, S. 2001. Evaluation of cholestatic jaundice in Young Infants. - The Journal of Indian Pediatrics 38: 893-898.

May, J.E. 1995. View points on digestive diseases: Bone disease in cholestatic liver disease. - The Journal of Gastroentrology 108: 275-283.

Mbarek, S., Saidi, T. and Chaouacha-Chekir, R.B. 2012. Effect of Cadmium contaminated diet in controlling water behavior. - The Journal of Neuroendocrinology and Behavior 13: 65-73.
Moezi, L., Rezayat, M., Samini, M., Shafaroodi, H., Ejtemie, S.H., Ebrahim Khani, M.R. and Dehpour, A.R. 2004. Potentiation of anandamide effects in mesentric beds isolated from bile ductligated rats: Role of nitric oxide optic tectom. The European Journal of Pharmacology 489: 5359.

Moezi, L., Shafaroodi, H. and Dehpour, A.R. 2006. Involvement of nitrergic and opioidergic systems in the hypothermia induced by cholestasis in rats. - The Journal of Pathophysiology 13: 227 232.

Molina, M.A., Martinez-Hugue, F., Asensi Monozo, M.T., Brines Solanes, J. and Codoner Franch, P. 1998. Cholestatic-type hepatits in childhood. - The Journal of Anales Españoles de Pediatría 49: 253-256.

Otsubo, H., Onaka, T., Suzuki, H., Katoh, A., Ohbuchi, T., Todoroki, M., Fujihara, H., Yokoyama, T., Matsumoto, T. and Ueta, Y. 2010. Centrally administered relaxin-3 inmduces Fos expression in the osmosensitive areas in rat brain and facilitates water intake. - The Journal of Peptides 31: 1124-1130.

Reyes, H. and Simon, F.R. 1993. Intrahepatic cholestasis of pregnancy: an estrogen - related disease. - The Journal of Seminar in Liver Disease 13: 289-301.

Rodrigo, R., Cauli, O., Gomez, U., Agusti, A., Hernandez, V., Garcia, J. and Felipo, V. 2010. Hyperammonemia Induces Neuroinflammation That Contributes to Cognitive Impairment in Rats With Hepatic Encephalopathy. - The Journal of Blood 115: 2231- 2239.

Rothuizen, J. 2009. Important Clinical Syndromes Associated with Liver Disease. Veterinary Clinics of North America Small Animal Practice Journal 39: 419-437.

Takahashi, A., Ishimaru, H., Ikarashi, Y., Kishi, E. and Maruyama, Y. 2001. Opposite regulation of body temperature by cholinergic input to the paraventricular nucleus and supraoptic nucleus in rats. - The Journal of Brain Research 909: 102-111.

Vincent, V.A.M., Tilders, F.J.H. and Van Dam, A.M. 1998. Production, regulation and role of nitric oxide in glial cells. - The Journal of Mediators of Inflammation 7: 239-255. 
Wright, G., Davies, N.A., Shawcross, D.L., Hodges, S.J., Zwingmann, C., Brooks, H.F., Mani, A.R., Harry, D., Stadlbauer, V., Zou, Z., Wiliams, R., Davies, C., Moore, K.P. and Jalan, R. 2007. Endotoxemia produces coma and Brain swelling in bile duct-ligated rats. - The Journal of Hepatology 45: 1517-26.

Yool, A.J., Brown, E.A. and Flynn, G.A. 2009. Roles for novel pharmacological blockers of aquaporins in the treatment of brain oedema and cancer. - Proceedings of the Australian Physiological Society 40: 71-78.

Zarrindast, M.R., Hoseindoost, S. and Nasehi, M. 2012. Possible interaction between opioidergic and cholinergic systems of CA1 in cholestasisinduced amnesia in mice. - The Journal of Behaivioural Brain Research 228: 116-124. 